\title{
REEXAMINING THE OLD DEPOT MUSEUM IN SELMA, ALABAMA, USA
}

\author{
JUNSHAN LIU ${ }^{*}$ \& DANIELLE WILLKENS ${ }^{2 \dagger}$ \\ ${ }^{1}$ McWhorter School of Building Science, Auburn University, USA \\ ${ }^{2}$ School of Architecture, Georgia Institute of Technology, USA
}

\begin{abstract}
Housed within the distinctive architectural fabric of the former L\&N Railroad Depot and listed on the Water Avenue Historic District National Register of Historic Places, the Old Depot Museum depicts life in Alabama and the histories that made Selma the "Queen City of the Black Belt." Formally known as the Selma/Dallas County Museum of History and Archives, collections range from the times of prehistoric American Indians to the Civil War, continuing through the Depression and the historic path of the Civil Rights Movement, illustrating how a site that was once home to a Confederate foundry became a critical repository for the preservation and interpretation of key documents, artifacts, and photographs related to "Bloody Sunday", as one of the most significant incidents of American Civil Rights Movement, and its aftermath. Through enlightening and enriching displays, Selma's Old Depot Museum provides unparalleled educational opportunities for the general public and area schools, with particular respect to the path from slavery to voting rights for African Americans. This paper presents a research project that brought the architectural fabric and archives of the Old Depot Museum in Selma to life, both on-site and remotely through Heritage Building Information Modelling (HBIM) and other technology, including LiDAR, $360^{\circ}$ photography, photogrammetry, and UAVs. The findings of this project offer a workflow for digitally documenting and showcasing other cultural heritage sites, underscoring the importance of redundancy in digital captures and platform flexibility for information integration and dissemination.
\end{abstract}

Keywords: $360^{\circ}$ photography, building information modelling, cultural heritage, heritage building information modelling, LiDAR, photogrammetry, terrestrial laser scanning, UAV, virtual tour.

\section{INTRODUCTION}

Housed within the distinctive architectural fabric of the former L\&N Railroad Depot and listed on the Water Avenue Historic District National Register of Historic Places, the Old Depot Museum (Selma, Alabama, USA) depicts life in Alabama and the histories that made Selma the "Queen City of the Black Belt." The red brick, stone trimmed building in the Romanesque Revival style was built around 1,890 (Fig. 1). Its unique survival and the broad aesthetic appeal make it one of twelve railroad depots in the southeast of the US designated by Southern Living as one of architectural and historical importance. The museum's collections range from the times of prehistoric American Indians to the Civil War, continuing through the Depression and the historic path of the Civil Rights Movement, illustrating how a site that was once home to a Confederate foundry became a critical repository for the preservation and interpretation of critical documents, artifacts, and photographs related to "Bloody Sunday" and its aftermath. The Old Depot Museum provides a greater context for understanding both the struggle for Civil Rights and Selma's current demographics and socioeconomics. However, with such a strong educational mission, the museum and its collections are known to few outside of Selma [1].

\footnotetext{
* ORCID: https://orcid.org/0000-0003-4476-5673
}

+ ORCID: https://orcid.org/0000-0003-3271-6890 


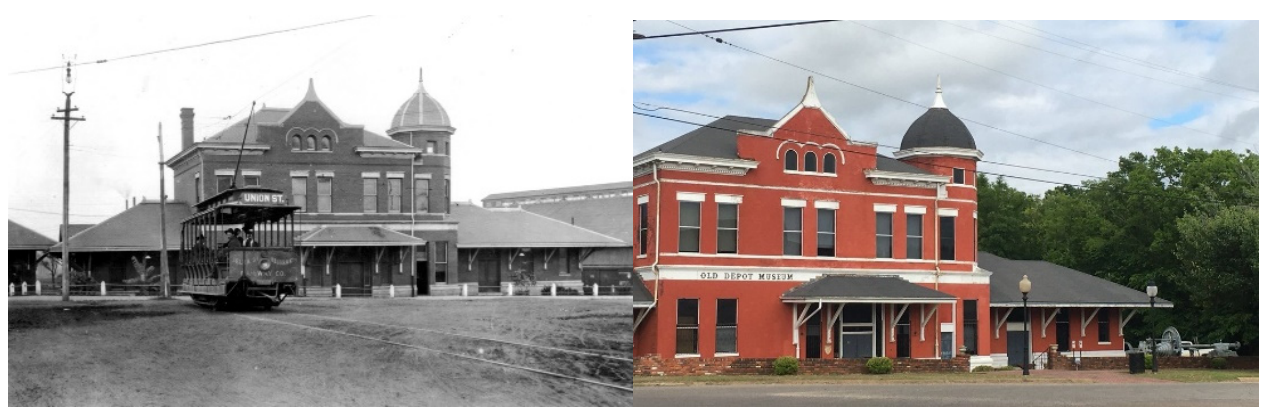

Figure 1: (a) A historic photo (c.1905) from the L\&N Railroad archives; and (b) A current view showing the front of the Old Depot Museum, Selma, Alabama, USA. (Source: https://www.archdsw.com/odm.html.)

In order to proceed towards a full preservation and restoration project for this significant building, and to make the rich collections of the museum more visible to the general public, this paper outlines a research project that brought the architectural fabric and historic archives of the Old Depot Museum to life for historians and visitors, both on-site and remotely through Heritage Building Information Modelling (HBIM) and other building digital documentation technology, including LiDAR, $360^{\circ}$ photography, photogrammetry, and UAVs.

\section{LITERATURE REVIEW}

According to UNESCO, cultural heritage includes tangible culture (such as buildings, monuments, landscapes, etc.), intangible culture (such as folklore, traditions, language, and knowledge), and natural heritage. All of them reflect universal values that must be a legacy [2]. Architectural documentation is considered one of the first processes that must take place for the preservation of heritage buildings, including both public and private buildings. The emergence of the digital revolution and how it leverages modern technologies provide new ways to document, interpret, and restore historic structures. Due to the historical value of these buildings and their status within both local and national heritage contexts, it was deemed important for these locations to be archived in a way that expands the breadth of dissemination and facilitates ease of access for scholars and researchers [3]. Documentation records the past and current conditions of resources at a level of detail for a variety of uses. Based upon these records, resources may be reconstructed, restored, and studied by professionals and academics [4]. Through a review of the published literature, the researchers have identified two types of digital technologies: one used to digitally capture and record the historic buildings and heritage sites, another used to digitally reconstruct them.

\subsection{Digitally capturing and recording of heritage buildings}

Over the last few decades, a technological revolution brought with it new tools to improve and accelerate the topographic techniques of spatial data acquisition to generate accurate construction information models [5]. Today's most influential techniques are photogrammetry, terrestrial laser scanning (TLS), and $360^{\circ}$ photography [5], [6].

\subsubsection{Photogrammetry}

Photogrammetry is a precise, non-invasive and contactless 3D measurement technique where high-quality image captures facilitate the collection of semantic and spatial data of a building 
or object to be accelerated [5]. Photogrammetry is a technique based on triangulation, where the lines of vision for the cameras, which are located in several places, are joined at a common point in the object. The results obtained with the photographic survey are orthographic images or models of triangulated and textured surfaces. However, due to the intensive requirement of manually processing of data, photographic reconstruction can be disadvantageous when the texture of the object is poor, or its shape is very complex [5].

\subsubsection{Laser scanning}

Laser scanning technologies are adopted for their ability to expedite the spatial data collection of existing buildings or complex surfaces, as well as for the accuracy and precision of the acquired data [5]. Laser scanners are subdivided into two specific areas: aerial and terrestrial. Each one has an associated range and precision that are suitable for the use to which it will be destined. Terrestrial Laser Scanning (TLS) technologies work via a laser beam that travels towards the area being scanned and back, measuring angles and distances with accuracies from millimetres to centimetres (Fig. 2(a)). In this context, TLS can obtain a precise and detailed geometric reproduction of three-dimensional objects in a short time, in the form of millions of points (a cloud of points), with geometric coordinates (X, Y, Z) (Fig. 2(b)), in a digital environment, with both metric and radiometric information [5].

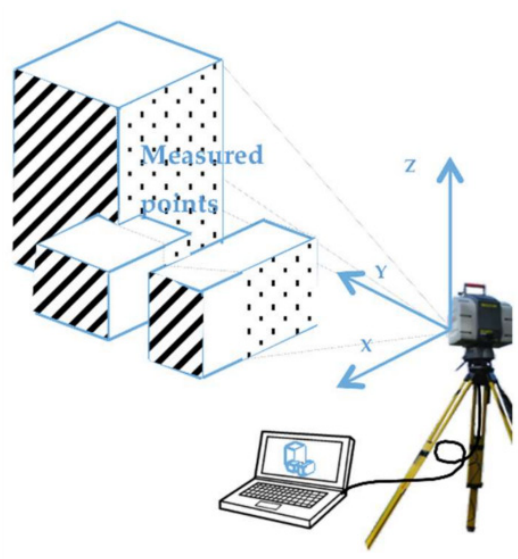

(a)

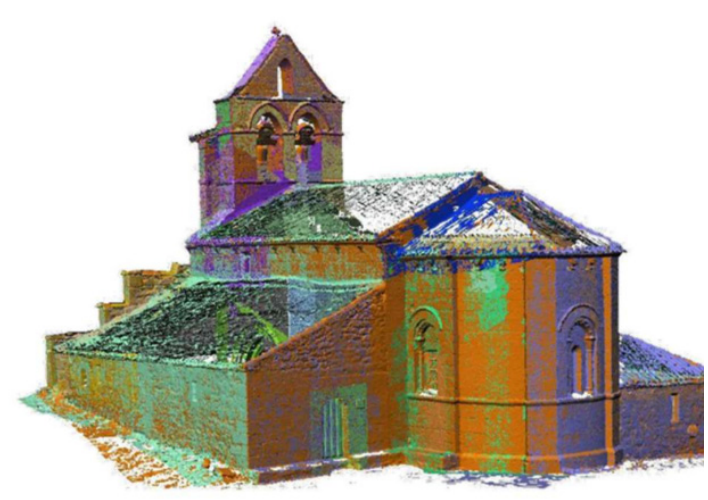

(b)

Figure 2: (a) Laser scanning process to create a point cloud; and (b) Georeferenced point cloud, $(\mathrm{X}, \mathrm{Y}, \mathrm{Z})[5]$.

According to López et al., TLS plays a very important role in a wide range of purposes that can be directly extrapolated to cultural heritage, including the follow-up of an intervention, defect detection, or the reproduction of existing models [5]. However, the high cost of these technologies, the need for specialized management, and the pre-processing of the information acquired can be considered as challenges and disadvantages. Also, it is not generally possible to capture all the geometric information of some objects or external surfaces from a single scanning position, since there may be elements that block the scanner's view. For this reason, it is necessary to place the scanner in different positions with respect to the object. The data extracted from the different scans creates partial-point clouds, and then each one of these point clouds is merged through a process called registration to generate 
a global cloud that will describe the site [4]. TLS can be complicated by difficult-to-reach parts of a buildings, such as the rooftop; therefore, another technology, UAV photogrammetry, can be deployed to capture images that can be used to create point clouds to create a comprehensive documentation of the building [7], [8].

\subsubsection{0-degree (or $360^{\circ}$ ) photography}

The term 360 -degree or $360^{\circ}$ technology refers to the concept of working with $360^{\circ}$ images, which are often called photo spheres (or photospheres) [9]. Many manufacturers offer $360^{\circ}$ cameras, yet the basic idea always remains the same: when such a camera is triggered, it captures one photo through each of its two (or more) lenses at the same time. Then, the camera 'stitches' the photos together to one $360^{\circ}$ photo. This way everything around the photographer is thoroughly captured. Thus, $360^{\circ}$ technology fills the gaps for typical, single aperture analogue or digital photographic captures, providing more immersive documentation for a building or a site. The $360^{\circ}$ photos can be uploaded online as a "virtual tour" of a built structure which allows public users to tour the building's interior and exterior. A main advantage of virtual tour is that viewers can easily orient themselves within the virtual site, understanding both where they are and what they are going to see next [9].

\subsection{Digitally reconstructing heritage buildings through heritage building information modelling (HBIM)}

Building Information Modelling (BIM) is a widespread technology in the new-build construction sector; however, it is not commonly used when it comes to heritage preservation [10]. Because BIM can represent the actual conservation state of the analysed building(s) in a virtual environment [6], researchers have argued that BIM can become an invaluable decision-making and management tool for historical assets. According to Adami et al., HBIM represents a very promising tool for the management of Cultural Heritage, both for daily operations and for the planned preservation of the asset itself and it requires a specific effort to adapt tried and tested tools and methods for new construction to existing Cultural Heritage buildings [10]. There are many software tools to perform the modelling and complete threedimensional documentation of the intervened structures. However, the Architecture, Engineering and Construction (AEC) sector adopted the BIM standard over the last few decades due to the progress that has been made in its qualities and capabilities. The complex modelling of cultural heritage through commercial BIM software leads to the consideration of the concept of Historic/Heritage BIM (H-BIM or HBIM), which pursues the modelling of architectural elements, according to artistic, historical, and constructive typologies. In addition, HBIM is an emerging technology that enables researchers to understand, document, advertise, and virtually reconstruct the built heritage [11].

However, the digital reconstruction procedures associated with historic buildings are not straightforward: the objects associated with historic models consist of components whose heterogeneous, complex, and irregular characteristics and morphologies are not represented in the BIM software libraries. Therefore, it is essential to introduce the historical and technical approaches into the BIM environment, as well as the TLS or photogrammetry point clouds and $360^{\circ}$ photography, to model the different virtual parametric components and achieve a "BIM as-is model" of the architectural heritage [5], [12]-[14]. Researchers have proposed a method to work in a $3 \mathrm{D}$ environment throughout the modeling process and to develop semantics during the construction phase, which enables geometric accuracy and reliability of visualization outputs [15]. 


\section{METHODOLOGY AND FINDINGS}

The development of comprehensive digital documentation for the Old Depot Museum consists of both the built fabric of the building and the archival digitization of documents to make them more accessible to researchers and general public across the globe. Due to the large-scale collections (e.g., canons) and integrated (i.e., wall affixed) displays traditional, analogue surveying is precarious. The research team used both traditional Historic American Buildings Survey (HABS) methods [16] and technological tools for digital documentation and restoration. These methods allowed the team to try different techniques for a geomatics approach, integrating TLS points of view through a LiDAR system as well as UAVs to monitor the site in different seasonal and lighting conditions. For example, repetitive 3D LiDAR scans and photogrammetry captures generate point cloud data which facilitate iterative studies of the building's weathering, fostering a foundation for a much-needed historic structures report that will lead to essential, large-scale preservation and restoration projects. The researchers also determined an appropriate Level of Knowledge (LOK) for this project, in order to ensure the HBIM model to provide suitable alphanumerical and graphical outputs for strategic decision-making on the major guidelines of heritage management: research, protection, conservation and dissemination [17]. A list of the digital documentation technological tools that have been utilized to date by the research team includes:

- $\quad$ TLS LiDAR: to capture 3D point cloud and panoramic photographs of built structures and site mapping of the area.

- UAV Aerial Photogrammetry: to complement the TLS LiDAR scans, especially to capture the condition and character of roofline.

- HBIM: to digitally reconstruct an 'as-built' model of the historic structure and store historical archives.

- $\quad 360^{\circ}$ Photogrammetry: to capture a virtual tour of the building and some of the archival assets of the museum. Data is used to help generate the HBIM model and published to the public audience.

\subsection{Data capture through TLS (point cloud)}

The data capture by TLS was carried out with a FARO Focus3D X130 HDR (FARO X130) laser scanner (Fig. 3(a)). FARO X130 is considered one of the higher-end laser scanners available on the market for ACE industries. It has a range from $0.6 \mathrm{~m}$ to $130 \mathrm{~m}$, with a measurement speed up to 976,000 points per second and an accuracy of $\pm 2 \mathrm{~mm}$ [18]. It also has capability of High Dynamic Range (HDR) photo recording. The TLS point cloud capture task was divided in two stages to accurately capture the data onsite and then correctly register the scans [12].

- On-site scanning using the FARO X 130 laser scanner

- Processing the scans to create the point cloud

\subsubsection{On-site scanning}

The research team spent time developing a "scanning map" prior to the field work (Fig. 3(b)), in order to ensure a good coverage of the building's exterior and interior and to have sufficient overlaps among the scans, which was critical for post-processing of the scans and developing a global point cloud. A total of eighty-four (84) scans were captured on three different trips to the Old Depot Museum. All of these scans were performed using a medium resolution (between 12 to 20 million points captured by each scan) with a complete field of view $\left(360^{\circ}\right.$ 


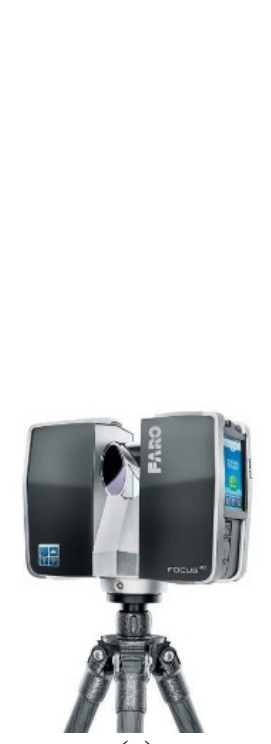

(a)

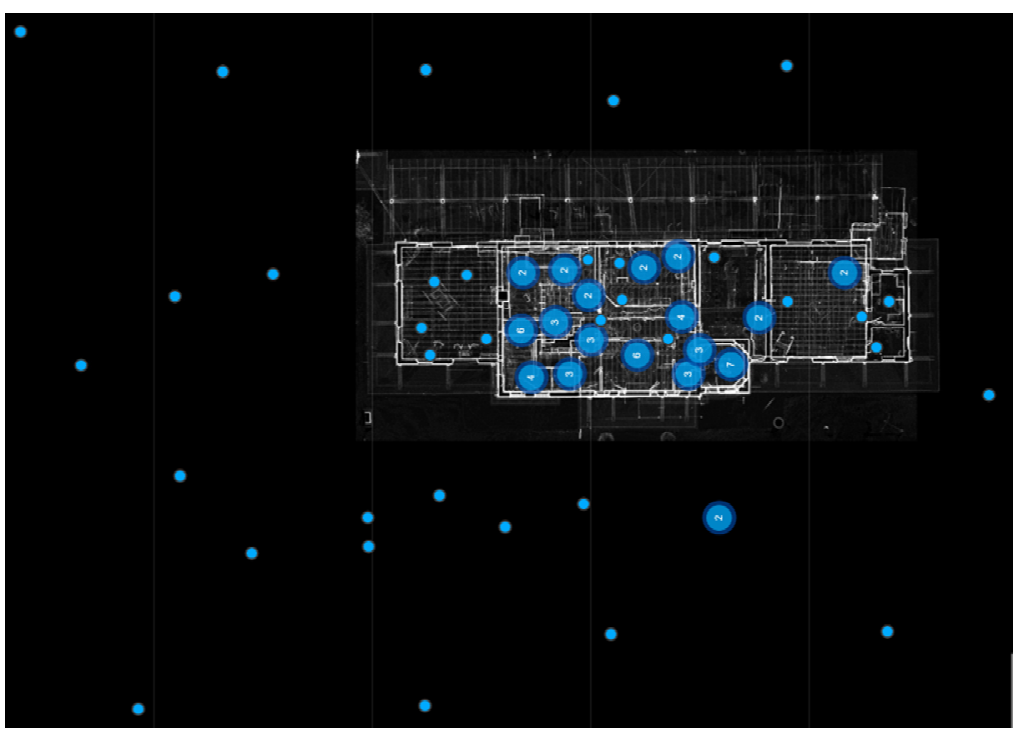

(b)

Figure 3: (a) FARO Focus3D X130 HDR laser scanner; and (b) An overview map showing locations of the TLS scans on the ground level.

in the horizontal plane and $270^{\circ}$ in the vertical plane). Panoramic photos were also taken by the scanner for colorizing the point clouds. On average, each scan took about 15 minutes including scan station setup, laser scanning, and capturing panoramic photos.

\subsubsection{Processing scans and creating point clouds}

Two software programs were used to process the scans: FARO SCENE and Autodesk ReCap Pro. The research team used both software programs previously on other projects. With the large number of scans captured for the Old Depot Museum, the team decided to use FARO SCENE to conduct initial data processing and register all of the 84 scans together into one single point cloud [19], and then transfer the data into ReCap Pro for further cleaning, manipulation, and preparation of the data for BIM modelling in the next stage [20].

Each scan was imported into FARO SCENE, the points were colorized using the panoramic photos during the processing. Due to the large number, the 84 scans were divided based on their locations into the following five 'clusters' to help manage the scans and expedite the registration: basement, level-1, level-2, attic and exterior. Table 1 shows the details of the scan 'clusters' and the registration results. The mean point error in the scan registration reports indicated the mean distance separation between two scans or scan clusters. The successful registration result of the majority of the scans was a result of the relatively high density of scans captured (as evidenced by high value in scan overlaps) and a good scanning plan; however, the registration of scans in the basement had relatively large errors due to the low scan overlap caused by the cumbersome materials stored in the space. Overall, the size of the processed point cloud in FARO SCENE format was over $140 \mathrm{~GB}$.

After scan registration in FARO SCENCE, the point cloud data was exported and transferred to Autodesk ReCap Pro where it was cleaned by removing unusable or errant points from both the interior and exterior of the building. Following an optimization process, 
a 'clean' point cloud for the whole building consisting of over 688 million points was created. The file size of this point cloud is 26 GB. The research team also used ReCap Pro to create still images of the point cloud for visualization purposes. Fig. 4(a)-(d) illustrate the cleaned point cloud in ReCap Pro. To further decrease the point cloud file size, it was exported to a 'unified' project in ReCap Pro with $5 \mathrm{~mm}$ spacing. The final point cloud had a file size of 5.2 GB and was ready to be used for BIM modelling.

Table 1: Details of the field scans and registration results.

\begin{tabular}{|l|c|c|c|c|}
\hline \multirow{2}{*}{ Scan clusters } & Building square & \# of scans & \multicolumn{2}{|c|}{ Scan registration result } \\
\cline { 4 - 5 } & footage covered & captured & Mean point error & Min scan overlap \\
\hline Basement & $552 \mathrm{ft}^{2} / 51 \mathrm{~m}^{2}$ & 6 & $0.31 " / 7.9 \mathrm{~mm}$ & $9.8 \%$ \\
\hline Level-1 & $4,163 \mathrm{ft}^{2} / 387 \mathrm{~m}^{2}$ & 19 & $0.04 \% / 0.9 \mathrm{~mm}$ & $24.9 \%$ \\
\hline Level-2 & $1,823 \mathrm{ft}^{2} / 169 \mathrm{~m}^{2}$ & 23 & $0.04 \% / 0.9 \mathrm{~mm}$ & $16.1 \%$ \\
\hline Attic & $1,823 \mathrm{ft}^{2} / 169 \mathrm{~m}^{2}$ & 13 & $0.05 \% / 1.3 \mathrm{~mm}$ & $16.3 \%$ \\
\hline Exterior & - & 23 & $0.06 \% / 1.6 \mathrm{~mm}$ & $9.0 \%$ \\
\hline Total: & $8,361 \mathrm{ft}^{2} / 776 \mathrm{~m}^{2}$ & 84 & & \\
\hline
\end{tabular}

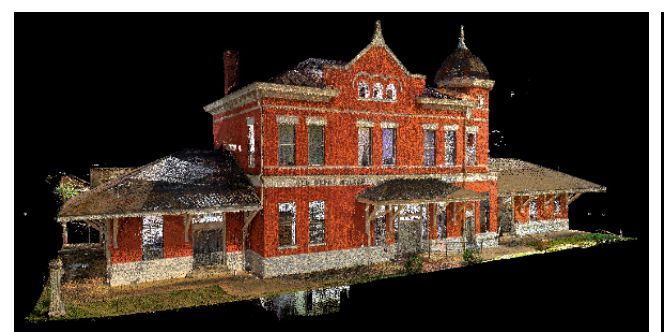

(a)

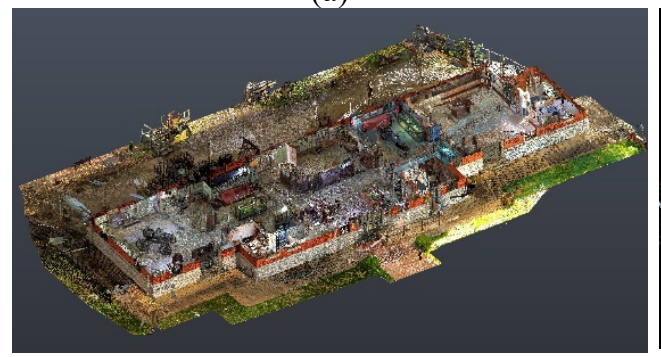

(c)

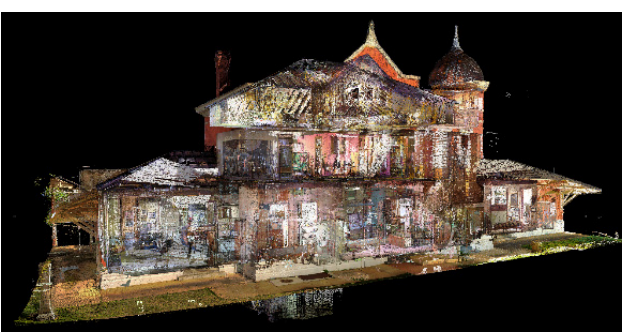

(b)

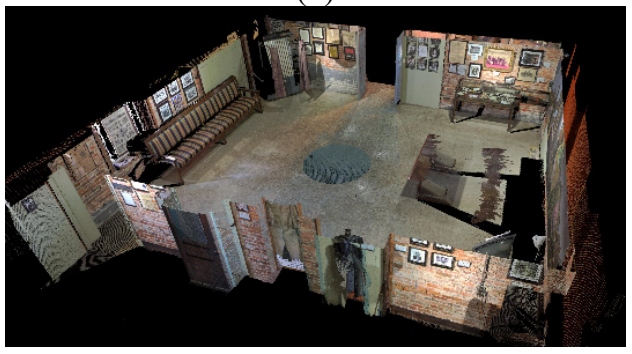

(d)

Figure 4: Photos of the registered point of the Old Depot Museum in FARO SCENE. (a) Front view; (b) Clear front view; (c) Level-1 sectional view; and (d) Plan cut of the Civil Rights room.

\subsection{Point cloud to heritage BIM (HBIM)}

There are a number of BIM platforms but few interface with existing structures, especially those of historic importance, because it is difficult to express unique construction details, settlement and irregular structural issues, and changes over time. For these reasons, the virtual and detailed reconstruction of historic structures has revealed some limitations of BIM platforms, such as the unavailability of historical parametric object libraries and the lack of 
tools for managing complex, irregular, and uncertain shapes that are obtained from point clouds [5], [12].

Autodesk Revit was selected as the BIM platform for this project by the researchers due to their familiarity with this software - one of the team members is an Autodesk Revit Certified Professional and has many years of experience of using and teaching Revit. The approach adopted by the research team for developing a HBIM model of the Old Depot Museum was to fully replicate the critical current structural data of this historical building, including the building's geometry and materiality. However, due to the limitations of Revit software, historical marks such as patina (i.e., wear and tear on the building), structural and aesthetic markings from settlement and renovations, and other damage to the structure might not to be fully addressed in the HBIM model. Also, it was the researchers' understanding that the information that was unable to be captured through field surveys or not visually exposed would not be included in the model (e.g., floor joists, subfloors, foundations, concrete reinforcements, etc.). As a HBIM model, it is required that every object introduced is not only a geometric representation of real shapes or technical components as in the CAD system, but it is a multi-data collector on its own, with specific significance to the user of the model. These elements provide an abstract computer representation of a physical world: a wall, as an object, represents an actual wall in the physical world as well as a door as a digital object represents a real door, perhaps connected to the hosting wall [12].

To create a real HBIM model of the museum, the research team associated the additional information of historic fabric such as photos and narratives to specific elements in the BIM model. This was accomplished through the creation of a set of new BIM Project Parameters and then assigning information (i.e., materials and specific finish of walls, hardware, photos, notes, etc.) to these Project Parameters of the specific elements.

Besides the point cloud captured by TLS technology that was used as the main source of information for the BIM modelling, one historic plan of the building (Fig. 5), and photos taken during field surveys from the ground and by a UAV were also used as references. The workflow for developing the HBIM model of the Old Depot Museum is illustrated by Fig. 6 . Fig. 7(a)-(h) demonstrate detailed steps of creating a small section of the HBIM model. An add-on application, FARO As-Built for Revit (As-Built), was used by the research team during the early stages of the BIM modelling to improve productivity and accuracy. As-Built was produced by FARO Technologies, Inc. for modelling 3D building models from 3D point cloud data [20]. The two As-Built's point cloud modelling functions that the research team utilized on this project included:

- Create walls quickly and precisely directly in the point cloud. The As-Built software can automatically select the most appropriate wall type, based on the determined wall thickness. If no appropriate wall type can be found, a new adapted wall type is automatically created by As-Built.

- Fitting beams and columns. As-Built can place standard structural elements in the point cloud. Common beam and column profiles can be automatically recognized.

Due to the unique historic fabric and form of the structure, the researchers spent a large amount of time on creating individual model elements using Revit's 'Model In-Place Component' command to precisely digitally reconstruct the building in the HBIM model. The estimate for this project is that $70 \%$ of the modelling time was spent on those customized elements such as wall surface details and decorative elements such as trims, railings, and mouldings that account for less than $20 \%$ of the items in the model. One of the greatest advantages of Revit as a tool for the design of new buildings is its large library of standard 


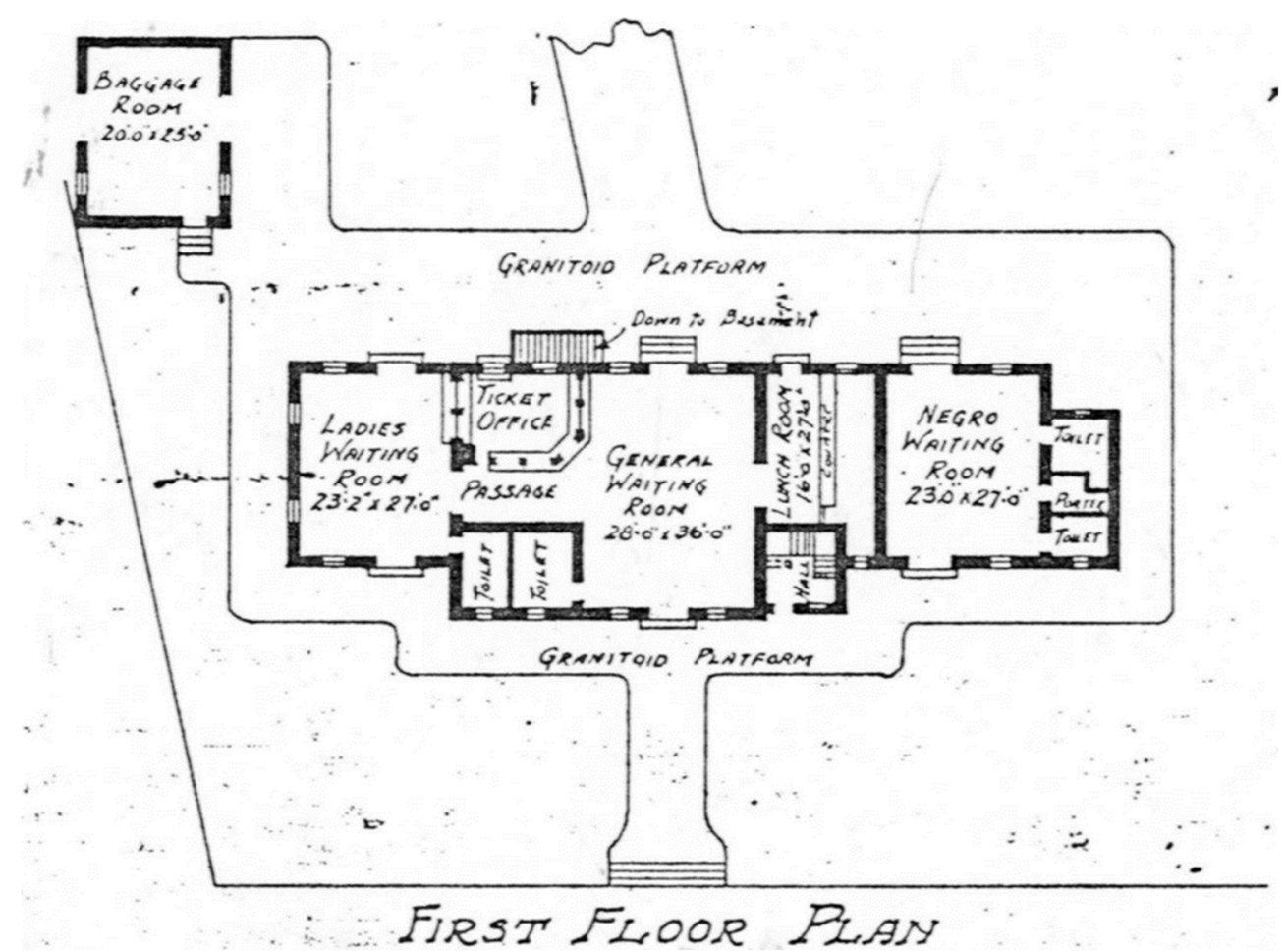

Figure 5: An original plan of the Old Depot Museum from the Louisville \& Nashville archives, showing the segregated waiting rooms. It was used as a supplemental reference of HBIM modelling.

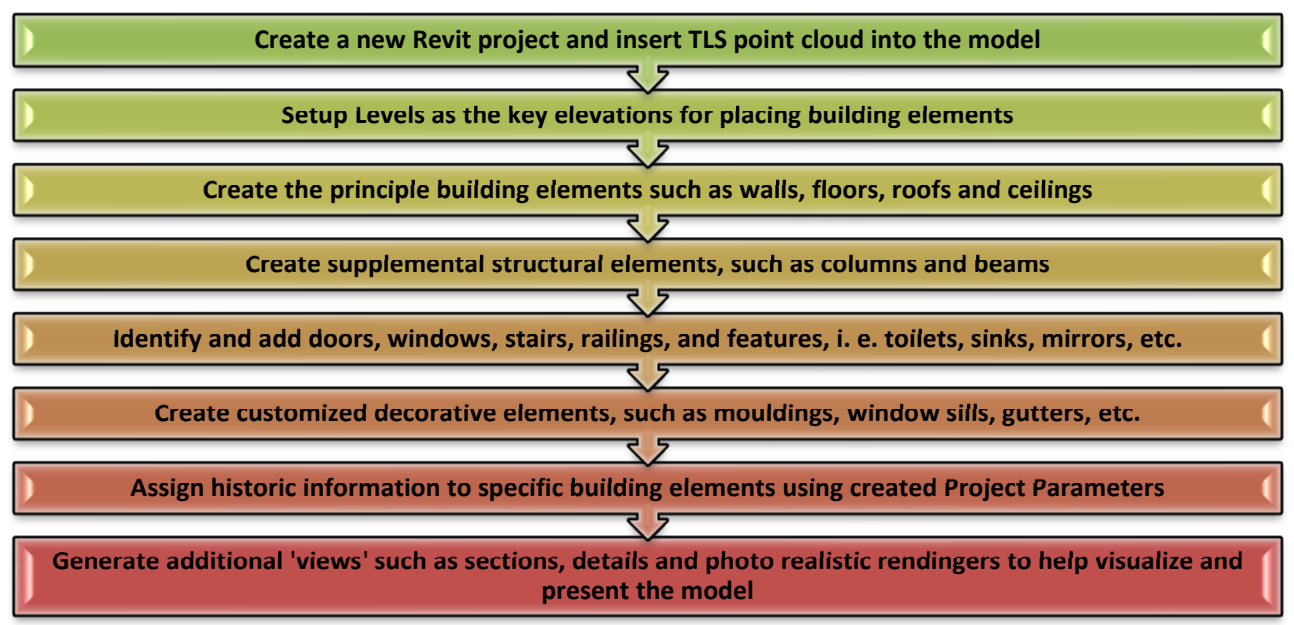

Figure 6: Workflow of HBIM model development. 


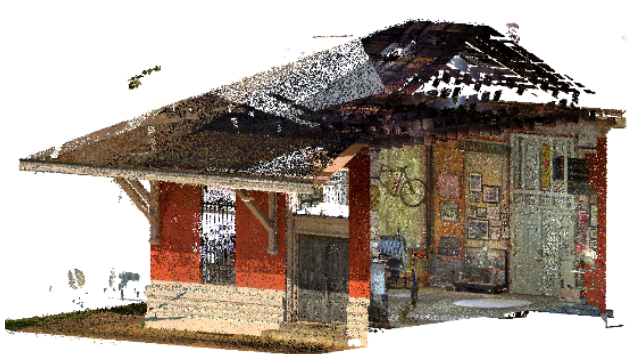

(a)

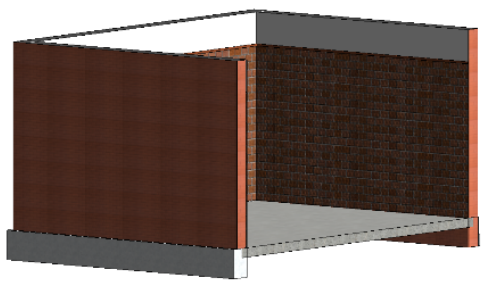

(c)

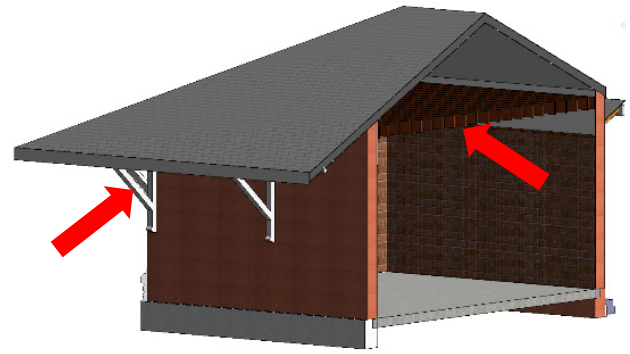

(e)

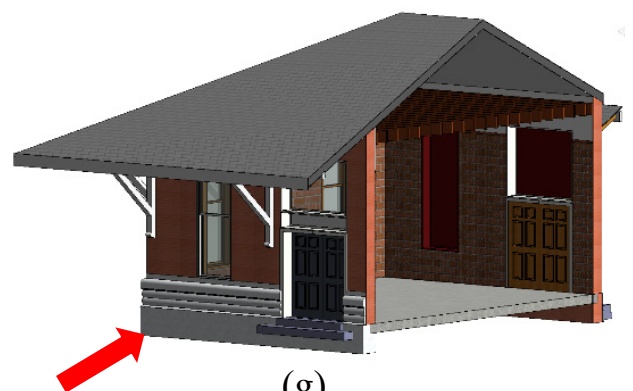

(g)

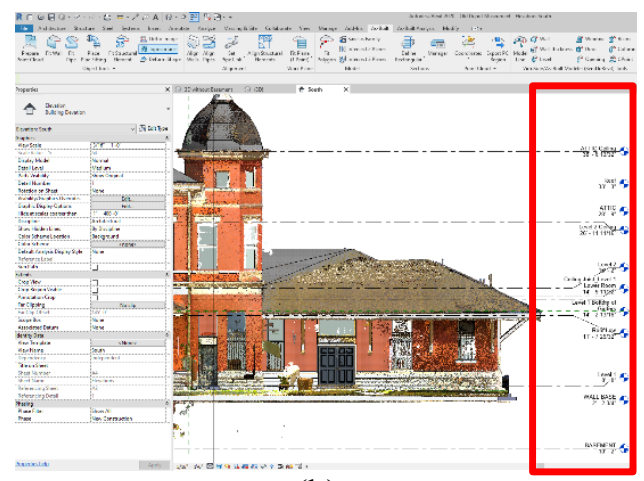

(b)

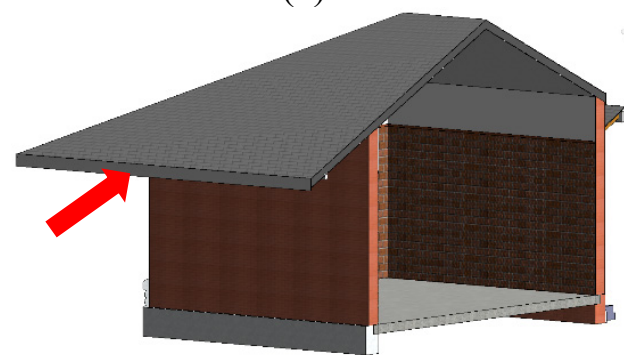

(d)

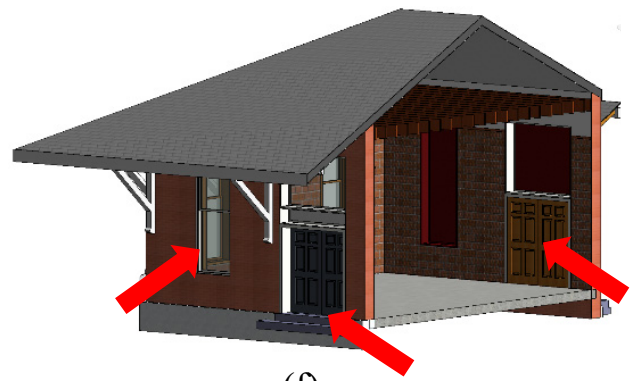

(f)

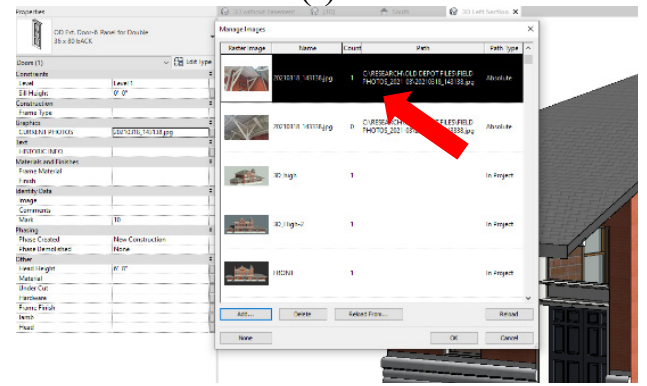

(h)

Figure 7: Detailed steps of the development of a small portion of the HBIM model.

(a) Insert point cloud into a new Revit model; (b) Set up levels (key elevations);

(c) Create walls and floors; (d) Create roofs; (e) Create structural elements;

(f) Add doors, windows and stairs; (g) Create wall sweeps and moldings; and

(h) Assign information and attributes to project parameters. 
model elements (Revit family files). Conversely, this is Revit's biggest disadvantage for heritage building modelling since the element library needs to be highly customized for a specific HBIM model. A full HBIM model of the Old Depot Museum can store data of the building's geometry, materiality, and some of its historic fabric. This model can also be used as a basis for possible future development of complementary documentation that can be linked to necessary conservation and maintenance tasks and preservation planning for the museum [12]. Fig. 8(a)-(c) display a comparison of the Old Depot Museum as seen in a photo, BIM model rendering, and the actual model in Revit. Fig. 9(a)-(c) demonstrate details of the model of the ground floor.

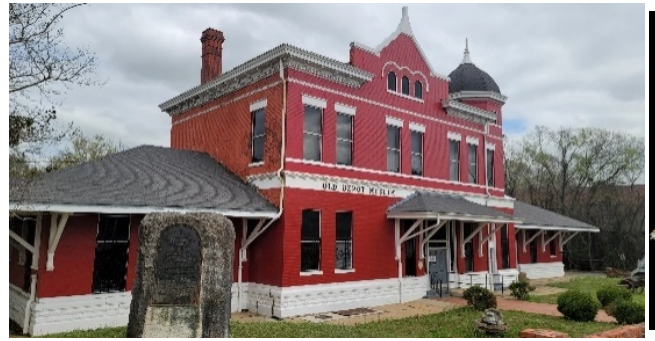

(a)

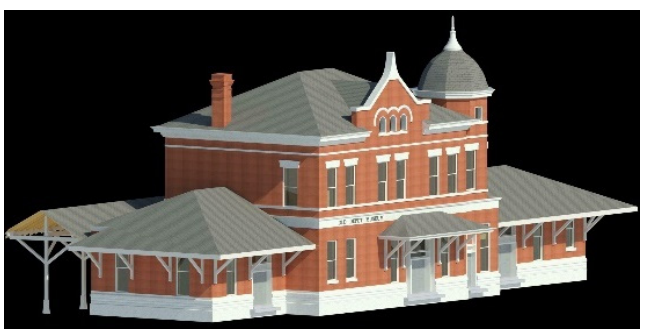

(b)

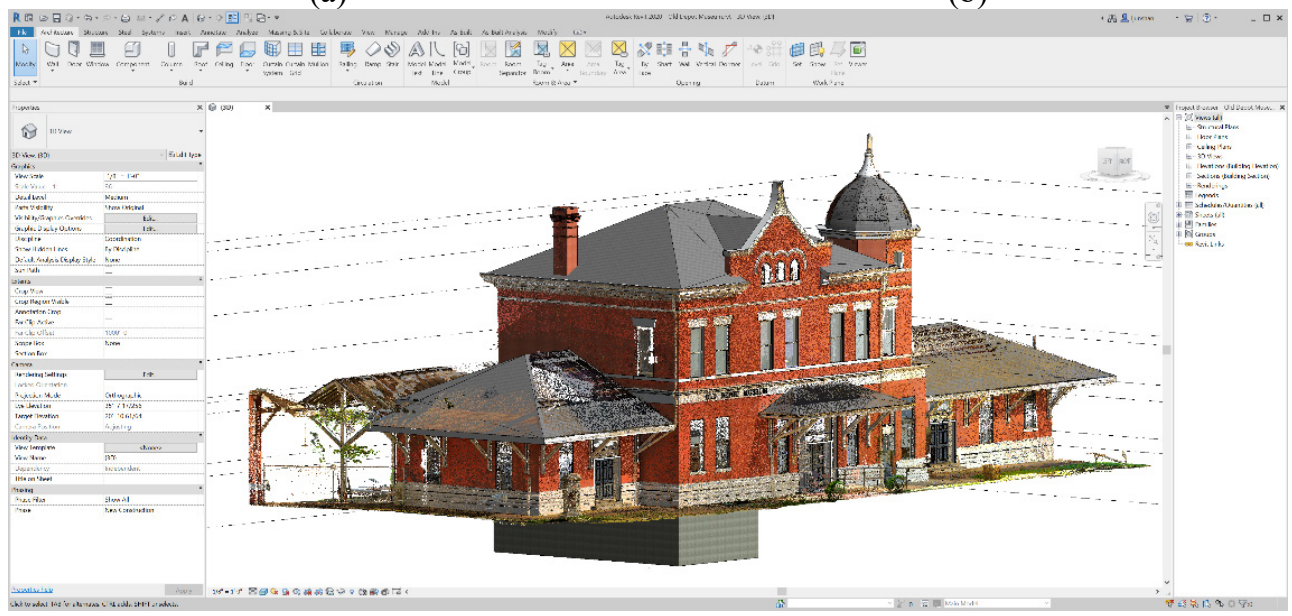

(c)

Figure 8: Comparison of the building's front façade, the HBIM model rendering, and its view in Revit. (a) Photo of the front view; (b) Rendering of HBIM model; and (c) A view of the HBIM model in Revit with the inserted TLS point cloud.

\section{$3.3360^{\circ}$ photography (virtual tour)}

A Matterport Pro2 3D Camera was used by the research team to capture a $360^{\circ}$ virtual tour of the Old Depot Museum. Matterport is a three-dimensional camera system that creates realistic, fully immersive virtual experiences, or a 'virtual tour' [21]. Using a virtual tour, viewers can explore the site from a variety of viewpoints and get a feel for the space without having to travel. This technology is an excellent choice for cultural spaces, such as a museum, 


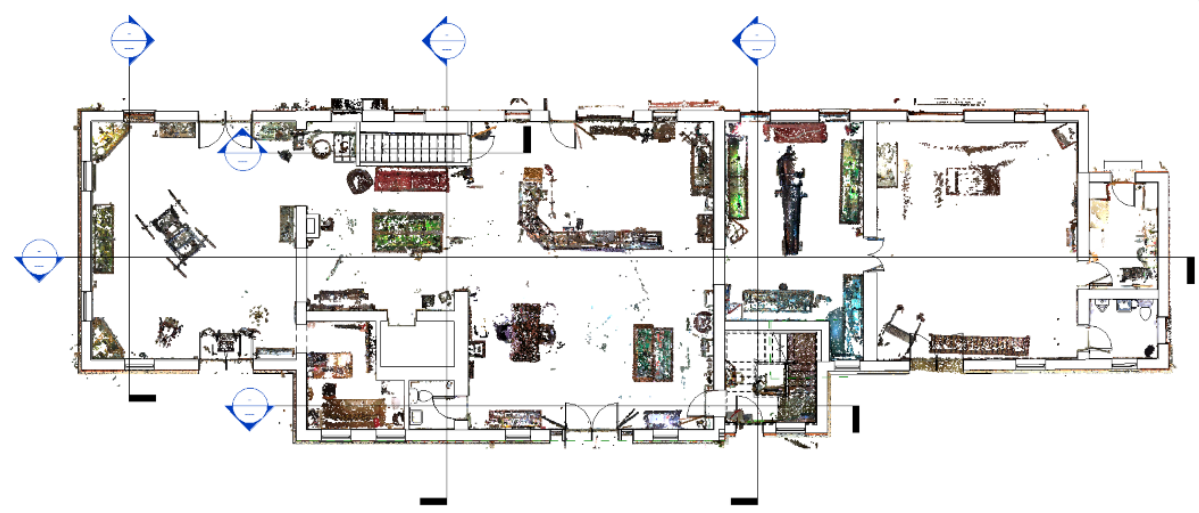

(a)

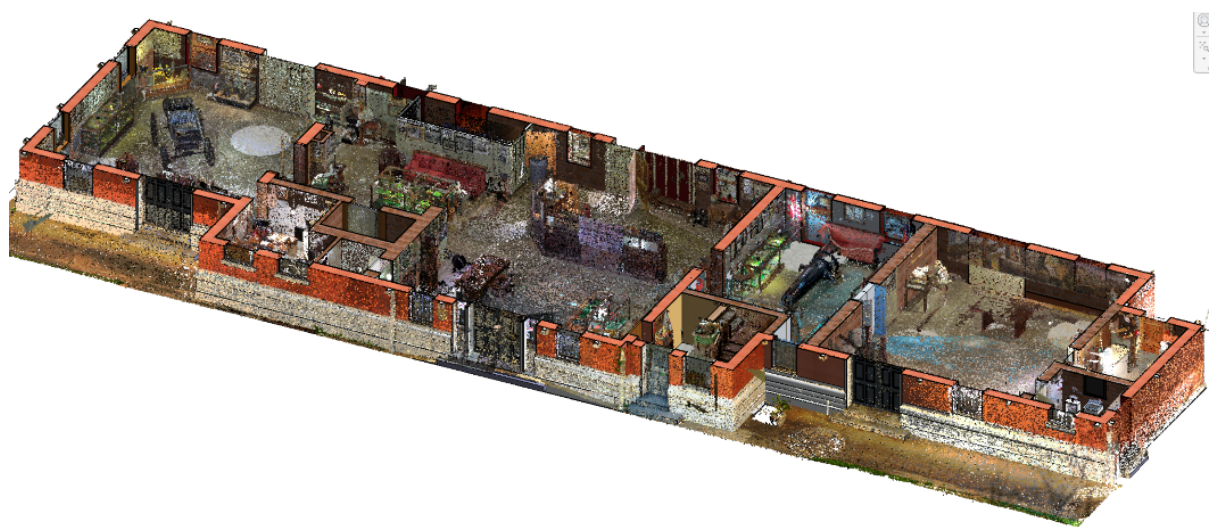

(b)

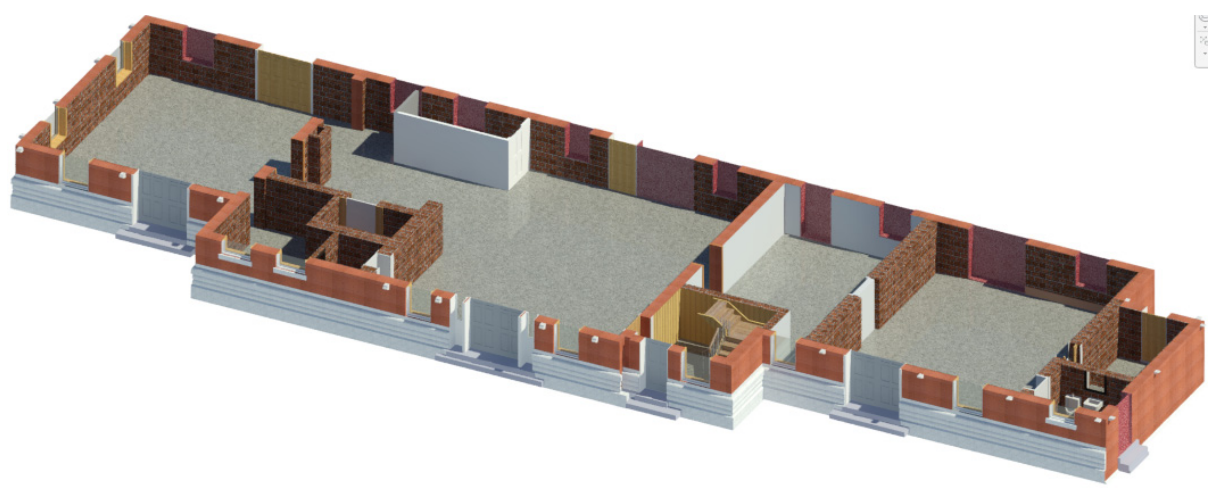

(c)

Figure 9: Details of the first floor of the HBIM model in Revit. (a) Ground-level floor plan view of the HBIM model in Revit with TLS point cloud displayed; (b) Groundlevel 3D sectional view of the HBIM model in Revit with TLS point cloud displayed; and (c) Ground-level 3D sectional view of the HBIM model in Revit with TLS point cloud display turned off. 
to offer the public an online exhibition and this has been particularly beneficial during the travel and physical restrictions associated with the Covid-19 pandemic. A few of the benefits of using Matterport's $360^{\circ}$ photography technology as listed on their website [21] include:

- High Quality: Matterport can create realistic virtual environments that make the viewer feel like they're really in the location. The renderings are also interactive. The viewers can view the space from virtually any angle and get a $360^{\circ}$ view while exploring from a first-person viewpoint.

- Precision: the camera system allows the users to scan up to 10,000 square feet per project. The results of the scan are dimensionally accurate, within $1 \%$, and can produce spatially accurate schematic floor plans.

- Versatility: Matterport is versatile and allows users to add additional information to the photography and share it.

However, there are several disadvantages of Matterport's $360^{\circ}$ photography technology, including: high service subscription cost, limited compatibility with many 3D cameras available on the market, relatively lower image quality for outdoor environments, significant time required for capturing and editing the virtual tours, and a lack of capability of working offline or extracting the data to other platforms. Despite the disadvantages, the research team was able to develop a $360^{\circ}$ virtual tour of the museum with a good coverage of both of its inside and outside, as shown in Fig. 10. This virtual tour has been published on the newly updated Old Depot Museum's website (https://selmamuseum.org/virtual-tour). This virtual tour has also assisted the research team in the development of the HBIM model by providing high-quality visual references of the building.

The research team evaluated the possibility of using the 'raw' point cloud data and the Revit model to create a virtual tour. However, many issues surfaced from this approach, including: the public's interest in photorealistic imagery vs. the ephemeral views of the point cloud data, difficulty of hosting the large model, lack of interactive features for the viewers to navigate independently and explore certain items in detail. It is also worth noting the reluctance of private or governmental owners (the Old Depot Museum is owned by the City of Selma) to share highly accurate and detailed data (point clouds or HBIM models) of historic sites with the public due to security concerns. Photographic tours, however, are typically viewed with less hesitancy.

\section{CONCLUSION}

As an adaptive reuse project that transformed the L\&N Railroad Depot, listed on the Water Avenue Historic District National Register of Historic Places, into the Old Depot Museum, this site in in Selma, Alabama is a significant historical and architectural structure. A research team consisted of an architectural historian, architectural designer, construction scholar, and digital documentation experts using Terrestrial Laser Scanning (TLS), UAVs, HBIM, photogrammetry, and $360^{\circ}$ photography technologies on a research project that digitally documented and reconstructed a digital twin the Old Depot Museum for preservation planning and the building's architectural fabric and historical archives were brought to life through a separate virtual tour.

TLS LiDAR scanning precisely documented the geometry of the Old Depot Museum. The researchers' field measurements and verifications augmented the 3D scanning data; the resulting drawings and structural studies were also supplemented by aerial images captured by an UAV, a documentation process not yet fully explored within the Secretary of the Interior's Standards for heritage documentation. This method provided detailed views of 


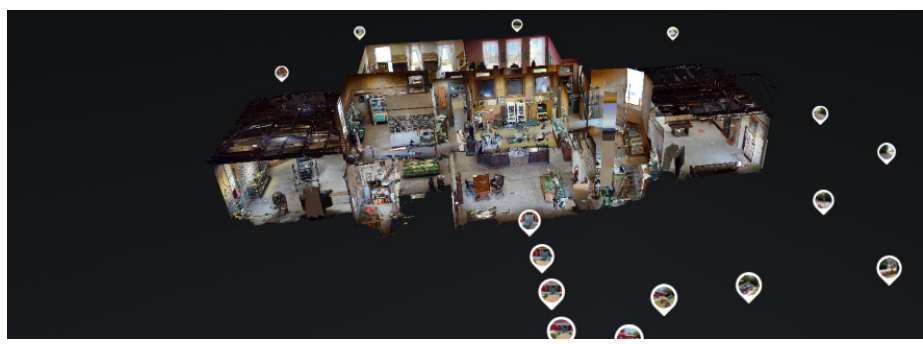

(a)

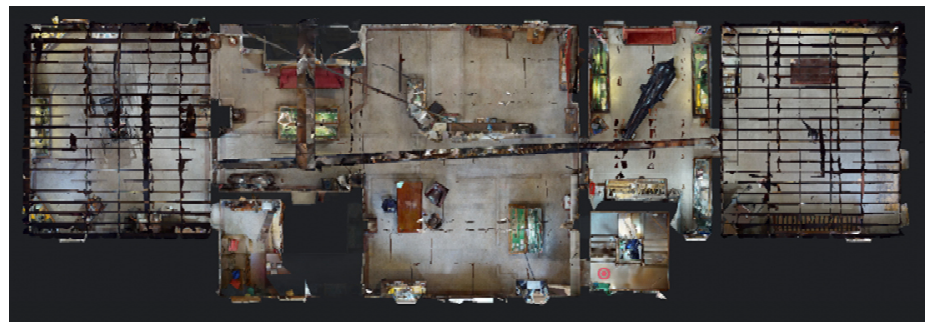

(b)

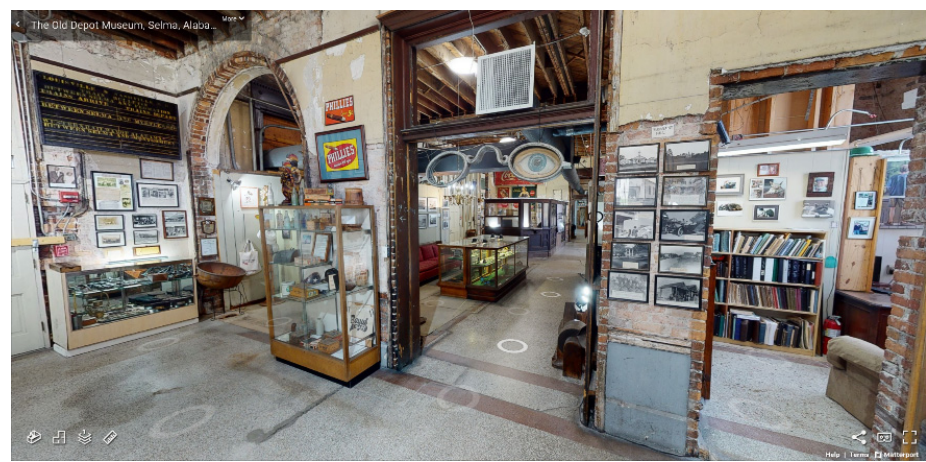

(c)

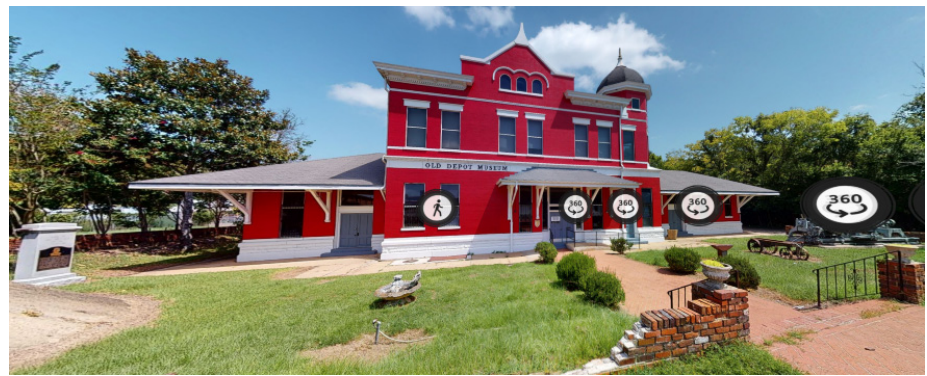

(d)

Figure 10: A virtual tour of the Old Depot Museum presented by Matterport $360^{\circ}$ photography technology. (a) Dollhouse view of the virtual tour providing an overall representation of the building; (b) Ground-level plan view in the Matterport virtual tour; (c) A full-screen view of the virtual tour that allows the viewers to explore from a first-person point of view; and (d) A view of the building's primary façade as seen in the Matterport virtual tour. 
hard-to-access areas without invasive or costly procedures. Between the point clouds generated from the 3D TLS LiDAR scans and UAV aerial photogrammetry, the digital documentation techniques yielded a model that was accurate to less than one eighth of an inch [1]. Then, the processed point cloud data was inserted into a Building Information Modelling (BIM) software platform, Autodesk Revit, for development of a 3D BIM model. With the precision of the 3D point cloud data and the assistance of an artificial intelligence (AI) aided modelling add-on, FARO As-Built for Revit, the researchers were able to create an accurate BIM 'as-built' model to restore the geometry and material data of the Old Depot Museum.

A substantial issue for BIM applications at historic structures is the irregularity of historical built fabric. Existing BIM tools focus on designing and buildings from scratch, such as Revit, and they are much less effective when working with existing, historic assets [9]. Because Revit's libraries and tools focus on the design and construction of new buildings with simple, regular, and standardized objects [4], the researchers had to spend a majority of their time on creating a relatively small amount of customized building elements, to fully replicate the genuine condition of the building. Furthermore, additional information was assigned to specific building elements to make the model a real Heritage BIM (HBIM) model. One of the disadvantages of LiDAR point cloud data and HBIM models is that neither of them can be easily presented to the public. Due to the large files and graphics card intensive processing, only professionals have access to the necessary hardware and software. To supplement the digital documentation and make the data more accessible to public audience, Matterport technology was incorporated as a tool to capture a $360^{\circ}$ photography virtual tour. The virtual tour also served as a visual reference for developing the HBIM model.

The findings of this project can be implemented to help digitally document, restore, study, and showcase other heritage structures. In future projects, the researchers plan to develop a more streamlined process to fully integrate the strengths of hardware and software, and increase the compatibility of the data captured and created to minimize time lost due to software transfers and redundant form building. They will also experiment with additional artificial intelligence (AI) aided applications similar to the FARO As-Built for Revit software to improve the efficiency of HBIM modelling. Finally, when the museum reopens following the Covid-19 pandemic, they will use 3D printing to augment on-site information displays for the public.

\section{REFERENCES}

[1] Willkens, D.S., Haley, H.M. \& Liu, J., Race, space, and digital interpretation at Selma's Old Depot Museum. Arris: The Journal of the Southeast Chapter of Architectural Historians, 31, pp. 108-119, 2020.

[2] Vecco, M., A definition of cultural heritage: From the tangible to the intangible. Journal of Cultural Heritage, 11(3), pp. 321-324, 2010.

DOI: 10.1016/j.culher.2010.01.006.

[3] Alsabban, R., Utilizing virtual reality technology in the preservation of architectural heritage: An empirical study of the local architecture of Hijazi identity in the Mecca region of Saudi Arabia. WIT Transactions on the Built Environment, vol. 191, WIT Press: Southampton and Boston, p. 113, 2020. DOI: 10.2495/STR190101.

[4] Gogo, M.E., Digital documentation for historic resources, a thesis submitted to the Graduate Faculty of the University of Georgia, 2011.

[5] López, F.J., Lerones, P.M., Llamas, J., Gómez-García-Bermejo, J. \& Zalama, E., A review of heritage building information modelling (H-BIM). Multimodal Technologies and Interaction, 2(2), p. 21, 2018. DOI: 10.3390/mti2020021. 
[6] Pocobelli, D.P., Boehm, J., Bryan, P., Still, J. \& Grau-Bové, J., BIM for heritage science: A review. Heritage Science, 6(1), p. 30, 2018.

DOI: 10.1186/s40494-018-0191-4.

[7] Abbas, M., et al., Three-dimensional data quality assessment: Unmanned aerial vehicle photogrammetry and mobile laser scanner. Engineering Journal, 25, pp. 143-154, 2021. DOI: 10.4186/ej.2021.143.

[8] Liu, J., Jennesse, M. \& Holley, P., Utilizing light unmanned aerial vehicles for the inspection of curtain walls: A case study. pp. 2651-2659, 2016. DOI: 10.1061/9780784479827.264.

[9] Construction Junkie, How $360^{\circ}$ images take construction documentation to the next level. https://www.constructionjunkie.com/blog/8 Aug. 2017/how-360-images-takeconstruction-documentation-to-the-next-level. Accessed on: 26 Apr. 2021.

[10] Adami, A., Bruno, N., Rosignoli, O. \& Scala, B., HBIM for planned conservation: A new approach to information management, p. 41, 2018.

[11] Strelka Magazine, BIM for heritage: How to develop a historic building information model. https://strelkamag.com/en/article/bim-to-the-rescue-of-heritage-sites. Accessed on: 26 Apr. 2021.

[12] Rodríguez-Moreno, C., Reinoso-Gordo, J.F., Rivas-López, E., Gómez-Blanco, A. Ariza-López, F.J. \& Ariza-López, I., From point cloud to BIM: An integrated workflow for documentation, research and modelling of architectural heritage. Survey Review, 50(360), pp. 212-231, 2018. DOI: 10.1080/00396265.2016.1259719.

[13] Koehl, M., Schneider, A., Fritsch, E., Fritsch, F., Rachedi, A. \& Guillemin, S., Documentation of historical building via virtual tour: The complex building of baths in Strasbourg. Remote Sensing and Spatial Information Sciences, XL-5/W2, pp. 385390, 2013. DOI: 10.5194/isprsarchives-XL-5-W2-385-2013.

[14] Napolitano, R., Scherer, G. \& Glisic, B., Virtual tours and informational modelling for conservation of cultural heritage sites. Journal of Cultural Heritage, 29, 2017.

DOI: 10.1016/j.culher.2017.08.007.

[15] Quattrini, R., Malinverni, E.S., Clini, P., Nespeca, R. \& Orlietti, E., From TLS to HBIM. High quality semantically-aware 3D modeling of complex architecture. Remote Sensing and Spatial Information Sciences, XL-5-W4, pp. 367-374, 2015. DOI: 10.5194/isprsarchives-XL-5-W4-367-2015.

[16] Historic American Buildings Survey/Historic American Engineering Record/Historic American Landscapes Survey - Digitizing the Collections, 1930. www.loc.gov/pictures/collection/hh/digitizing.html. Accessed on: 27 Apr. 2021.

[17] Castellano-Román, M. \& Pinto-Puerto, F., HBIM oriented towards the master plan of the charterhouse of Jerez (Cádiz, Spain). Remote Sensing and Spatial Information Sciences, XLII-2/W15, pp. 285-290, 2019.

DOI: 10.5194/isprs-archives-XLII-2-W15-285-2019.

[18] FARO Laser Scanner Focus3D X 130 HDR Tech Sheet.pdf powered by box. https://faro.app.box.com/s/lz4et2dd6zxk2dwtijmxgvu7yi3m9tve/file/441635448354. Accessed on: 27 Apr. 2021.

[19] SCENE Software. https://www.faro.com/en/Products/Software/SCENE-Software. Accessed on: 27 Apr. 2021.

[20] ReCap Software Get Prices and Buy ReCap Pro 2022 Autodesk. https://www.autodesk.com/products/recap/overview. Accessed on: 27 Apr. 2021.

[21] Complete Guide to Matterport What is Matterport and More. https://www.designblendz.com/blog/guide-to-matterport. Accessed on: 28 Apr. 2021. 